\title{
O conselho fiscal e a governança corporativa: transparência e gestão de conflitos
}

The advisory board and corporate governance: transparency and conflict management

\section{João Eduardo Prudêncio Tinoco}

Doutor em Contabilidade e Controladoria pela FEA/USP

Professor do Mestrado em Administração da Universidade Católica de Santos

Endereço: Rua José de Albuquerque Medeiros, 388, Bairro Água Fria

CEP: 02336-000 - São Paulo/SP - Brasil.

E-mail: tinocojoao@uol.com.br

Telefone: (11) 2924-2519

\section{Sergio Antonio Loureiro Escuder}

Mestre em Gestão de Negócios pela UNISANTOS

Prof. Titular da Faculdade de Administração de Empresas na UNISANTA

Rua Valdomiro Silveira, 11 apto 11

CEP: 11.055-150 - Santos/SP - Brasil

E-mail: sergio@impakto.srv.br

Telefone: (13) 3223-8083

\section{Mariano Yoshitake}

Doutor em Contabilidade e Controladoria pela FEA/USP

Professor do Mestrado em Administração das Faculdades Alves Faria (ALFA)

Endereço: Av. Paulista, 2239, apto. 51, Bairro Jardins

CEP: 01311-300 - São Paulo/SP - Brasil

E-mail: kimimarinamariano@gmail.com

Telefone (11) 5575-5637 


\title{
Resumo
}

O objetivo deste artigo é pesquisar a opinião dos membros do conselho fiscal das empresas classificadas na Bolsa de Valores de São Paulo, nos níveis 1, 2 e novo mercado, quanto ao cumprimento (compliance) das práticas de governança corporativa previstas para os conselhos fiscais das Instituições. As técnicas utilizadas, nesta pesquisa de caráter descritivo, para a obtenção de informações foram as entrevistas, as observações e os questionários (com perguntas do tipo fechado, construído por intermédio de afirmativas com os métodos da escala de Likert). A listagem das empresas nos níveis 1, 2 e novo mercado foi feita em 2007. O resultado da pesquisa evidencia que os conselheiros fiscais têm, efetivamente, conhecimento de suas responsabilidades e de que as referidas práticas geram valor aos acionistas. Observou-se que as empresas embora cumpram com os conceitos de boa governança não incluem na aplicação desse mecanismo o conselho fiscal, mantendo-o apenas dentro das regras previstas na legislação das sociedades por ações.

Palavras-chave: Conselho fiscal. Governança corporativa. Transparência. Evidenciação.

\begin{abstract}
The objective of this article is to survey the opinions of members of the Advisory Board of companies listed on the Bolsa de Valores de Sao Paulo (Stock Exchange of São Paulo), at levels 1, 2 and new market with regard to compliance of the corporate governance practices planned for the advice of tax institutions. The techniques used in this descriptive study, to obtain information were interviews, observations and questionnaires (with closed-type questions, constructed by means of statements to the methods of the Likert scale). The list of companies at levels 1,2 and new market was made in 2007. The research result shows that tax advisors have, in fact, aware of their responsibilities and that such practices generate value for shareholders. It was observed that although the companies comply with the concepts of good governance do not include the application of this mechanism the council tax, keeping just within the rules laid down in law of corporations.
\end{abstract}

Keywords: Advisory board. Corporate governance. Transparency.Disclosure.

\section{Introdução}

Ao analisarem a estrutura de propriedade das empresas nos Estados Unidos, Berle e Means (1932) observaram a prevalência de empresas de capital aberto com propriedade diluída entre vários pequenos acionistas minoritários. Contudo, La Porta et al. (1999) apresentam evidências de que, em 27 países desenvolvidos, se observa grande concentração do controle e da propriedade das empresas nas mãos de famílias e do Estado, ao invés da propriedade difusa proposta por Berle e Means (1932).

Pesquisa de La Porta et al. (1999), conclui que 64\% das grandes empresas nos 27 países mais desenvolvidos, apresentam acionistas controladores, sendo que, à exceção do Japão, esses controladores são famílias, muitas vezes descendentes dos fundadores dessas organizações.

No Brasil predomina a tradição do direito francês, este proporciona menor proteção legal aos investidores, segundo La Porta et al. (1998). Portanto é de se esperar alta concentração de capital nas empresas, principalmente no que se refere a capital votante. Nesse sentido, Siffert Filho (1998) examina as mudanças no controle societário das empresas brasileiras nos anos 90 . O autor estuda as 100 maiores empresas não financeiras, independentemente de o controle ser 
privado nacional, estatal ou estrangeiro. No caso brasileiro, o autor identifica o crescimento significativo da forma de controle compartilhado das corporações, possuindo como acionistas principalmente investidores institucionais, tanto nacionais como estrangeiros.

Essa questão fica mais evidente quando se infere que o estudo da governança corporativa no Brasil pode ser mais bem compreendido à luz do modelo desenvolvido do mercado acionário, iniciado nos anos de 1970, com a criação da Lei 6.385 de 07/12/1976, disciplinando o mercado de capitais e criando a Comissão de Valores Mobiliários - CVM, bem como a Lei 6.404 de 15/12/1976 que dispõe sobre as sociedades por ações.

Entretanto, apenas a partir da década de 1990, o assunto da governança corporativa se tornou objeto de vários estudos e pesquisas profundas no universo acadêmico, direcionando a discussão na formação e atuação do conselho de administração como instrumento de relação dos controladores com os minoritários e demais atores da organização como explicitam Brandão (2004), Almeida (2001), Bornholdt (2005) e LODI (2005).

A palavra governança, segundo Andrade e Rossetti (2004) foi utilizada pela primeira vez em 1991 e no ano seguinte foi definido o primeiro Código de Melhores Práticas de Governança Corporativa. $\mathrm{O}$ assunto governança corporativa surge com o Relatório Cadbury divulgado em dezembro de 1992. Note-se, portanto, que o assunto sobre governança corporativa não era discutida antes de 1990.

Contudo, verifica-se que apenas em 1995 foi editado o primeiro livro que continha a designação "Corporate governance" de autoria de R. Monks e N. Minow. Por outro lado, Oliveira (2006, p. 12-16) afirma que as primeiras discussões a respeito do assunto tiveram sua origem no tripé "firmado pelo fundo LENS, pelo relatório Cadbury e pelos princípios da OCDE (Organização para Cooperação e Desenvolvimento Econômico) e o filtro básico do processo corresponde à Lei Sarbanes-Oxley".

Kanitz e Kanitz (1978), Campos (2003) e Brandão (2004) expuseram que o relacionamento dos acionistas minoritários com majoritários ou controladores, na prática acaba por inviabilizar o mercado de capitais como mecanismo de financiamento para as empresas pela atuação desenfreada de expropriação dos acionistas minoritários. Segundo estudos de Santos, Rogers, Machado e Lemes (2006), as leis 10.303/2001, lei 9457/1997 e lei 64046/1976 são consideradas como política pública que reflete os padrões de governança. Para esses autores, o citado aparato legal beneficiam de forma direta os acionistas controladores. Isso permite maior expropriação por conta dos benefícios privados de controle.

A teoria da agência, ou conflito de agência está evidenciada em pesquisas feitas por acadêmicos, como Jensen e Meckling (1976), Ross (1973), Alchian e Demsetz (1972), em que descreveram que as empresas são entidades de relações 
de contratos e que essas relações são conflituosas, principalmente nas esferas mais alta de poder: conselho de administração e diretoria executiva. Segundo Jensen e Meckling (1976), a teoria da agência visa a analisar os conflitos e custos resultantes da separação entre a propriedade e o controle de capital, o que origina as assimetrias informacionais, os riscos e outros problemas pertinentes à relação principal-agente.

A boa governança corporativa no Brasil significa a adoção de mecanismos que possam induzir os administradores externos ou acionistas majoritários a proteger os interesses dos acionistas minoritários, maximizando o valor das ações com decisões que objetivem e visualizem o longo prazo, conforme Almeida (2001) e Silveira (2006).

Nesse contexto, a governança corporativa no Brasil se reflete na maior proteção aos acionistas minoritários por meio de ações como: melhor transparência nas informações e acesso desses atores aos atos da gestão por intermédio da eleição de conselheiros fiscais pelas assembléias de acionistas, em que esses novos atores têm por critério, fiscalizarem os atos do conselho de administração e da diretoria executiva, funcionando como um modelo semelhante ao comitê de auditoria, conforme conclui Lamb (2002).

Em razão da existência de uma previsão legal na Lei das Sociedades Anônimas, pela existência do Conselho Fiscal, art. 162 da Lei 6.404/76, o comitê de análise do mercado norte-americano, admitiu que as empresas que tiverem suas ações negociadas em bolsa de valores norte-americanas, poderiam substituir o comitê de auditoria pelo conselho fiscal, observadas algumas modificações técnicas e práticas de abrangência, conforme exposto por Strahota e Tafara (2005).

Essa postura acabou por transformar e fortalecer o conselho fiscal nas empresas, evitando que estas, além da existência desse conselho, fossem obrigadas a criar comitês de auditoria acarretando novos custos de agência às organizações.

Nesse diapasão, o Instituto Brasileiro de Governança Corporativa I.B.G.C. lançou em 2004 um estudo com o objetivo de trazer elementos para construir uma cartilha de regras básicas de atuação, postura, comprometimento, dedicação e ética do conselho fiscal, enquadrando nas práticas de boa governança corporativa.

Lamb (2002) expõe ainda que o papel do conselho fiscal situa-se além daquelas simples atribuições previstas na legislação, mas, sobretudo, naquelas em que estão subentendidas, como: controle e acompanhamento dos controles internos, planejamento estratégico e orçamentário já que faz parte do sistema de controle e fiscalização.

Neste contexto os conselheiros fiscais têm como papel o acompanhamento das decisões relevantes da empresa, como as questões relacionadas ao planejamento estratégico, riscos e controles internos para efeito de proteção não somente 
aos acionistas minoritários, mas, sobretudo ao mercado e assim corroborar com a proteção e perenidade da Entidade.

Assim, o objetivo deste artigo é pesquisar a opinião dos membros do conselho fiscal das empresas listadas na Bolsa de Valores de São Paulo, classificadas nos níveis 1, 2 e novo mercado, quanto ao cumprimento (compliance) das práticas de governança corporativa previstas para os conselhos fiscais das Instituições.

Assim, o objetivo específico é realizar um survey para identificar a percepção dos conselheiros fiscais entrevistados quanto à importância, adequação ou não das práticas contidas no guia de orientação ao conselho fiscal, pelo Instituto Brasileiro de Governança Corporativa.

A pesquisa também procurou identificar, na percepção desses conselheiros fiscais, a importância das práticas recomendáveis de governança para a criação de valor aos acionistas.

\section{Referencial Teórico}

No Brasil, nas décadas de 50 e 60 , o acionista controlador ou familiar tinha presença muito forte no mercado em que acumulava o papel de acionista majoritário com o papel de gestor da empresa (LODI, 2005).

Já nas décadas seguintes, entre 70 e 80 , começam a surgir os primeiros grupos de conselheiros de administração nas grandes empresas familiares brasileiras que, conforme Lodi (2005) tinham autonomia e iniciava-se o processo de divisão de poder entre os acionistas e os profissionais de gestão.

Nos anos 90, os conselheiros de administração ganham e ampliam seu poder nas empresas com a presença forte de investidores institucionais, a volta do capital estrangeiro e o início do processo de desestatização da economia brasileira.

Lodi (1998), Benhoeft e Gallo (2003) e Santos (1998) afirmam que surgiu, a partir daí, o aparecimento dos litígios e conflitos sobre as quebras dos bancos: Nacional, Econômico, Bamerindus e Noroeste.

O conceito inicial relativo à governança corporativa estava relacionado com o conselho de administração, diretoria executiva e os acionistas investidores que estão fora da gestão. Com o passar do tempo, amplia-se a definição sobre o tema, uma vez que as questões de poder nas organizações não se resumem apenas ao tripé: conselho de administração, diretoria executiva e acionista, mas também a toda a sociedade na qual a empresa está inserida.

O Instituto Brasileiro de Governança Corporativa (2005) descreve o conceito de governança corporativa como um sistema que assegura aos sócios proprietários o governo estratégico da empresa e efetiva monitoração da diretoria executiva. Essa relação se dá pelo conselho de administração, auditoria inde- 
pendente e o conselho fiscal, cujos papéis são fundamentais para o exercício do controle e assegura aos acionistas a equidade, transparência, responsabilidade pelos resultados e obediência às leis do País (IBGC, 2005).

Relatório das Organizações de Cooperação e Desenvolvimento Econômico - OCDE - (2002) refere que esse conselho de administração deve agir sempre com base em quatro princípios fundamentais:

1. Fairness - a justiça e equidade nos relacionamentos entre os acionistas, evitando que os majoritários sejam beneficiados em detrimento dos minoritários.

2. Disclosure - a transparência das informações relativas às empresas, evitando a ocorrência de informações privilegiadas;

3. Accountability - o dever e a responsabilidade pela prestação de contas;

4. Compliance - o estrito cumprimento da lei.

Bernhoeft e Gallo (2003) descrevem que a preocupação quanto ao tema da governança corporativa vem de longa data, conforme exposto anteriormente. Porém, os estudos mais profundos começaram a ser desenvolvidos no início da década de noventa.

Destarte, a governança corporativa é vista como um conjunto de princípios e práticas que têm sido incorporados aos modelos de gestão das empresas e tem atraído a atenção de diferentes partes interessadas e, em sentido mais amplo, o próprio interesse público.

Assim, as boas práticas de governança corporativa têm a finalidade de aumentar o valor da sociedade, facilitar seu acesso ao capital e contribuir para sua perenidade.

Na percepção de Souza (2004), a governança corporativa no Brasil pode ser vista à luz de três diferentes visões: a abordagem internacional, aquela segundo o Instituto Brasileiro de Governança Corporativa - IBGC e a terceira, à luz da Comissão de Valores Mobiliários - CVM, cada qual objetivando resguardar os direitos dos demais atores de uma organização, porém com a lente focada de forma diferenciada. Contudo, em todas elas a preocupação principal está com as relações de shareholders e stakeholders.

No Brasil, em razão da forte concentração de capital, os aspectos da governança corporativa possuem particularidades que extrapolam a administração interna da organização. Em função disso Bornholdt (2005) infere a questão da governança corporativa como normas de relações entre empresa, acionistas, família e seus herdeiros.

Segundo Mônaco (2000), acionistas controladores detêm em média $88 \%$ das ações com direito a voto. Já Leal e Valadares (2002) constatam que o maior acionista, é detentor em média de $58 \%$ das ações ordinárias, enquanto os três 
maiores acionistas juntos possuem 78\% destas ações.

Bernhoeft e Gallo (2003) entendem que a alta concentração de propriedade e do controle das companhias, aliada à baixa proteção legal dos acionistas, fez com que o principal conflito de agência no País se dê entre acionistas controladores e minoritários e não entre acionistas e gestores, como nos países anglo-saxões com estrutura de propriedade pulverizada.

Como decorrência da grande concentração de poder, os membros do conselho de administração são em sua maioria indicados pelo acionista controlador. Esta situação reduz a possibilidade de uma postura ativa e independente dos conselhos que é necessária para o cumprimento de suas atribuições legais de fixação da orientação geral dos negócios e fiscalização da gestão dos executivos em prol de todos os acionistas.

Com o objetivo de tentar neutralizar essa postura, outro ator aparece na estrutura da Governança Corporativa, o conselho fiscal. O fortalecimento desse órgão nas empresas que atuam no mercado norte americano surgiu com a autorização da Securities and Exchange Commission - SEC na aceitação do conselho fiscal como agente controlador em substituição ao comitê de auditoria.

Strahota e Tafara (2005) comentam que ao aceitar que o conselho fiscal substitua o comitê de auditoria nas empresas brasileiras listadas nos Estados Unidos, a SEC passou a lhe atribuir também as mesmas responsabilidades. Ainda de acordo com os autores, essas responsabilidades geram a necessidade de dominar um vasto conhecimento acerca de assuntos relevantes até agora não assumidos pelos conselheiros fiscais.

\subsection{Nascimento do Conselho Fiscal}

A concepção de um organismo fiscalizador dos negócios sociais ou em necessidade de fiscalização dos negócios das sociedades por ações já existia desde aqueles primeiros momentos da criação das companhias holandesas, como anota Valverde (1959).

Já outra corrente é unânime em reconhecer que o Código de Napoleão, datado de 1807, constitui um verdadeiro divisor de águas na história das sociedades por ações. Foi com o código francês que se estabeleceram as linhas gerais da sociedade mercantil, acabando com o privilégio que atendia aos interesses do Estado, dando-se acesso aos homens de comercio na formação das sociedades anônimas, consolidando-se essa forma (VALVERDE, 1959).

Esse código, no entanto, que não cuidou do conselho fiscal das companhias, inspirou toda a legislação posterior regulamentadora das sociedades. Salienta Valverde (1959) que a primeira lei a tornar obrigatório o conselho fiscal foi a lei francesa de 1867, embora a utilização de organismos fiscais nas companhias já 
representasse, à época, uma prática em consolidação.

Varias legislações passaram a conceber aparelhos e formas de fiscalização a partir da lei francesa de 1867, adotando-se sistemas diferentes, os comissairees aux comptes na França; o collegio sindacale na Itália; o conselho fiscal no Brasil e na Alemanha.

Adotando-se o controle externo, por intermédio de auditorias profissionais e com a criação de agencia estatal de fiscalização, surgiu o chamado sistema anglo-americano, a Securities and Exchange Comission - SEC, conforme Brandão (2004).

Algumas críticas aos Conselhos de Administração e Conselho Fiscal encontradas em pesquisas feitas por Booz, Allen e Hamilton (2003), mostram aspectos preocupantes no desempenho de governança nas empresas. Apontam, por exemplo, que a maioria dos conselhos de administração apresentou baixo grau de independência e diversidade em sua composição.

Da mesma forma, as pesquisas dessa empresa de consultoria organizacional sugerem que os papéis do conselho fiscal são percebidos como importantes pelos pesquisados. Porém, ressalvas ao seu desempenho foram frequentes nas entrevistas realizadas. Como exemplos, citam algumas observações feitas pelos participantes da pesquisa:

(a) o conselho fiscal não se integra ao funcionamento do conselho administrativo;

(b) só traz despesa, não sei se o gasto é positivo...;

(c) o conselho fiscal é um organismo para os minoritários serem a sua representatividade;

(d) o conselho fiscal existe, mas as funções são confundidas com o conselho de auditoria.

Segundo pesquisas da KPMG (2008), em 2003, a Securities Exchange Comission (SEC) concedeu uma permissão para que o Conselho Fiscal de empresas brasileiras abertas nos EUA exercesse as funções do Comitê de Auditoria. Entretanto, as empresas continuam bastante divididas entre aquelas que possuem um Conselho Fiscal atuando na função do Comitê de Auditoria e outras que optaram pela estruturação de um Comitê de Auditoria nos moldes estabelecidos para empresas norte americanas. Nesse contexto, note-se que os conselheiros fiscais de companhias brasileiras com ações listadas em bolsas norte-americanas foram eleitos para cumprimento da seção 302 da lei americana Sarbanes-Oxley (SOX). Nesse sentido, assumiram uma função dupla e desconhecida, mais ampla do que a de apenas fiscalizar as demonstrações financeiras: a de membro do comitê de auditoria. Ocorre que, ao aceitar que o conselho fiscal substitua o comitê de auditoria nas empresas brasileiras listadas nos EUA, a Securities and Exchange 
Commission (SEC) passou a lhe atribuir também as mesmas responsabilidades.

A complexidade do novo desafio do conselho/comitê já começa na operacionalização dos trabalhos. Desde que a SEC atendeu ao pedido da Comissão de Valores Mobiliários (CVM) para que fosse substituído o comitê pelo conselho fiscal, uma série de dúvidas surgiu em torno da duplicidade de funções e até de eventuais conflitos de interesses. Afinal, o conselho continua com as atribuições previstas pela lei brasileira - de fiscalizar a companhia em nome dos interesses dos acionistas, inclusive com representação dos minoritários -, enquanto o comitê deveria ter um papel mais próximo à gestão.

Como a adaptação do conselho acabou sendo a opção da maioria das companhias brasileiras emissoras de American Depositary Receipts (ADRs), sujeitas à SOX, o momento é de buscar uma identidade para este órgão inédito - e, dessa forma, evitar que seja visto com a desconfiança de alguém com duas faces.

As citadas pesquisas da KPMG mostram que a exigência relativa ao Comitê de Auditoria foi estabelecida pela Seção 301 da Lei Sarbanes-Oxley. O Comitê deve se subordinar ao Conselho de Administração e ser composto por no mínimo três membros desse Conselho, entre os quais deve haver pelo menos um especialista financeiro. Todos os membros devem atender às regras de independência em relação aos auditores externos.

\subsection{A Natureza Jurídica do Conselho Fiscal}

No Brasil, o conselho fiscal está compreendido nos artigos 161 a 165 da Lei $n^{\circ}$. 6.404- Lei das S/A- de 15 de dezembro de 1976, com modificações estabelecidas pela Lei 9.457 de 1997 e pela Lei 10.303 de 2001 .

Embora pela Lei das Sociedades Anônimas o conselho fiscal seja um órgão de existência obrigatória nas sociedades por ações, a mesma lei não exige sua instalação e funcionamento permanente.

Sua instalação pode ser exigida por acionistas e o órgão mantém-se até a próxima assembléia geral ordinária, quando os mandatos dos conselheiros fiscais se extinguem; as suas competências mais conhecidas e que derivam da Lei são:

1. Fiscalizar por qualquer de seus membros os atos dos administradores e verificar o cumprimento de seus deveres legais e estatutários;

2. Opinar sobre o relatório anual da administração e sobre os demonstrativos financeiros;

3. Opinar quanto aos atos dos administradores;

4. Denunciar por qualquer de seus membros ao conselho de administração e aos acionistas eventuais atos de irregularidades ou fraudes que venham a ser de seu conhecimento.

5. Comparecer a assembléia geral de acionistas e assembléia geral 
extraordinária e opinar sobre matéria de sua competência;

6. Analisar balanços e demonstrativos financeiros e emitir opinião.

O conselho fiscal presta contas aos acionistas, da sua fiscalização dos atos da diretoria executiva e do conselho de administração e oferece sua opinião quanto aos demonstrativos financeiros examinados pelo auditor externo. A atuação do conselheiro é uma atuação ao mesmo tempo colegiada e individual. Para Bulgarelli (1998), as funções determinadas pela lei para a atuação do fiscal envolvem uma larga faixa de atuação e avaliação subjetiva a ser preenchida pela iniciativa individual Segundo esse autor, a situação dos conselheiros fiscais se situa em dois planos: o plano da vinculação ao seu eleitorado e um outro plano ligado à situação do fiscal no âmbito do conselho, as projeções perante os outros órgãos e a sua vinculação ao regime de responsabilidade.

O conselho fiscal tem uma dúplice vinculação: com os acionistas que o indicaram e com a companhia; aos primeiros uma vinculação de confiança, de defesa dos interesses; a segunda, cumprindo suas funções com o limite no interesse social (BULGARELLI, 1998). Segundo esse autor, pelo aspecto funcional e sistemático, o conselho fiscal aparece como uma das formas de controle sobre a administração, abrangendo as contas e a gestão, ou somente as contas.

\subsection{Responsabilidades do Conselho Fiscal x Conselho de Administração.}

Toda a atividade empresarial sugere, intrinsecamente, a existência de risco, ou seja, o empresário investidor, ao aplicar seu dinheiro na empresa está buscando um retorno maior daquele oferecido pelos investimentos alternativos que existem no mercado.

Com o advento dos princípios da boa governança e da lei Sarbane Oxley em 2002, a controladoria, bem como os controles internos tornaram-se altamente estratégicos dentro das organizações.

Estudos de Tedlow e John Jr. (1986) e Rajan e Zingales (2000) evidenciam que com esses novos arranjos nas organizações, criam-se novas oportunidades para o desenvolvimento do patrimônio das empresas, pois a organização é administrada por pessoas com qualificações maiores, daquelas possuídas por apenas um proprietário ou um pequeno grupo de sócios.

Hart e Moore (1995) observam que os acionistas minoritários, não tendo a intenção e a vontade de comandar suas empresas, muitas vezes por sua ínfima participação e, ainda, os majoritários por não terem os requisitos mínimos necessários, transferem e delegam a grupos de executivos que são efetivamente aqueles que tomarão as decisões necessárias para levar e rentabilizar o capital investido pelos acionistas. 
Como essas decisões não podem ser apreciadas individualmente e a cada momento pelos acionistas, com risco de paralisar as atividades empresariais, torna-se inevitável que haja uma transferência de poder para as mãos desses administradores. Poder esse suficiente para que possam tomar as decisões na rapidez e agilidade que os negócios requerem.

Entretanto, esse poder não deve ser absoluto e indiscriminado, mas vinculado aos interesses exclusivos dos acionistas da organização. Para assegurar essa relação e diretriz dos acionistas, é instituído na empresa o conselho de administração, órgão exclusivamente constituído para representar os acionistas e proprietários com obrigação legal de agir como intermediário entre os investidores e os gestores da organização, conforme Allen e Galé (2000).

Esse conselho é investido de poder e ascendência de governança sobre os executivos na organização, tendo como princípio a orientação das ações, por meio de fixação da missão, objetivos e metas da empresa, consubstanciando com as expectativas dos acionistas e demais stakeholders, devendo, ainda, nortear as estratégias e as operações empresariais.

Na maioria das empresas, paradoxalmente, os administradores que detêm o poder de execução têm, também, o poder de informar o que fazem, tanto ao conselho de administração como aos acionistas.

Harris e Townsend (1981) consideram esse tipo de risco, ou seja, de executivos que executam, prestam contas, como risco de agenciamento. A partir desse posicionamento conflitante de governança, decorrente do risco de agenciamento, é que se constroem três fundamentais atribuições da governança corporativa moderna, voltadas ao controle da gestão dos recursos, que devem ser aplicadas para produzir valor aos acionistas.

O primeiro chamado de controle de custódia, cujo objetivo é assegurar que todas as obrigações contratuais e legais da organização sejam rigorosamente cumpridas pelos administradores, sem que ocorram fraudes, abusos de poder ou desvios de objetivos.

O segundo leva o nome de controle do desempenho dos recursos, cujo objetivo é assegurar que sejam aplicados de forma a gerar resultados e que esses resultados estejam em conformidade com as expectativas e percepção de risco do negócio.

Por último, o controle de veracidade e qualidade da informação, que tem o papel de informar os acionistas sobre a custódia e o desempenho dos recursos, tendo poder de influenciar diretamente a produção das informações, bem como o estabelecimento de métodos de mensuração e comunicação dos resultados da empresa. 
2.4 Riscos

A tarefa central da governança moderna é implantar na organização um conjunto de controles e incentivos para solucionar de forma integrada os problemas de custódia e desempenho dos recursos, dentro de um ambiente de risco.

Martin et al. (2004, p.11) definem três tipos de riscos empresariais.

1. Risco de propriedade = associados à mobilização, aquisição, manutenção e disposição dos ativos, à exceção dos ativos humanos; boa parte desses riscos é focalizada pelo controle de custodia pelo controle de desempenho e até o de qualidade da informação.

2. Risco de processo $=$ os que se originam do uso ou da operação dos ativos para alcançar os objetivos empresariais; a maioria dos riscos dessa área é focalizada pelo controle de desempenho, mas com alguns que se encontram na órbita da custodia e da informação.

3. Riscos comportamentais = vinculados à aquisição, manutenção, utilização e disposição de ativos empresariais de base humana, entre as quais, a capacidade de gestão.

Concluíram ainda, que tais riscos não são uniformes em todas as organizações, dependendo da atividade empresarial e setor da atividade.

Os riscos relacionados a fraudes, sabotagem, injúria, processos trabalhistas, preenchimento errôneo em contratos são comuns em todas as organizações, conforme desenvolvimento da pesquisa de Martin et al. (2004). Expõem ainda, que outros advindos de ameaças externas como mudanças tecnológicas são muito diferentes, dependendo do setor de atuação da organização.

Podem-se caracterizar esses riscos como: demandas de clientes ou fornecedores, alterações nas características de mercados de insumos ou de produtos (entrada de novos produtos substitutivos, aumento da intensidade da concorrência por meio de preços, etc.), mudanças na regulamentação governamental, políticas econômica e fiscal.

Riscos financeiros, muito embora possam ser classificados como riscos externos, dada sua importância para as instituições financeiras e para a área financeira das organizações, são considerados independentes.

Segundo Duarte Jr. (2003), riscos têm suas características especiais dada a natureza de seus ativos, sendo compostos por quatro grandes grupos: risco de mercado, risco operacional, de crédito e legal. Martin et al. (2004) e Duarte Jr. (2003) descrevem, ainda, que os riscos de processos incluem diferentes tipos de grupos de riscos, cada qual com suas peculiaridades cuja natureza do negócio é avalizadora.

Riscos de operações humanas: são aqueles de perdas totais ou parciais de recursos que estejam sendo processados, associadas às operações ou controles 
não apropriados dos ativos e direitos da empresa e que tem causa humana.

Fraudes e omissões são os riscos inerentes aos processos que se originam em deliberadas falsificações de atividades ilegais ou não recomendadas eticamente, bem como em distorções de informações feitas por empregados, fornecedores, clientes, administradores, etc., em nome da empresa ou contra ela.

Riscos de atitudes perante os riscos são os que resultam de uma demasiada cautela ou de um excesso de temeridade dos administradores, especialmente os da alta direção, em relação aos riscos que cercam as empresas, conforme March e Shapira (1987).

Como demonstrado por Martin et al. (2004), existe uma complexa e interminável lista de riscos a que uma organização está sujeita, além daquele considerado risco normal, ou seja, o risco de negócio. São riscos que estão relacionados à governança em que os controladores no momento da escolha de seus administradores, tanto do conselho de administração quanto da diretoria executiva, exigem deles o cumprimento dos contratos estabelecidos.

O estudo da KPMG (2008), quanto ao Conselho Fiscal, mostrou que:

1. A grande maioria (cerca de 76\%) das empresas com ADRs possuem Conselho Fiscal instalado. No outro extremo, observou-se que menos da metade das empresas pertencentes ao Novo Mercado (cerca de 40\%) possuem tal órgão de fiscalização em funcionamento.

2. Em relação à composição, observou-se que cerca de $47 \%$ dos conselheiros fiscais das empresas com ADRs foram indicados por acionistas minoritários, contra 36\% no grupo de empresas do Novo Mercado e apenas $19 \%$ no grupo de empresas representativas da população de listadas na Bovespa.

\section{Metodologia da Pesquisa}

Esta pesquisa, segundo Martins (2002), caracteriza-se como descritiva, pois se propôs esclarecer, na visão dos membros do conselho fiscal, até que ponto as boas práticas de governança corporativa estão sendo adotadas pelas empresas classificadas nos níveis 1, 2 e novo mercado da Bovespa e, ainda, identificar a percepção dos conselheiros fiscais sobre a importância e o impacto da utilização das práticas como ferramenta de criação de valor aos acionistas.

Identifica-se, ainda, como bibliográfica que, segundo Martins (2002) e Belém et al. (2004), é desenvolvida mediante o estudo de teses de doutorado, dissertações de mestrado, artigos científicos, revistas e jornais especializados, livros, anais de congresso e em sites da web.

Foram enviados questionários datados de 07/02/2007, para 150 conse- 
lheiros fiscais em atividade nas 65 empresas listadas e classificadas nos níveis 1,2 e novo mercado da Bovespa. Destas, 21 empresas não dispõem desse colegiado instalado. Dos questionários enviados, 40 conselheiros responderam. Os dados coletados estão apresentados de forma consolidada sem identificação dos respondentes e das empresas as quais estão vinculados, de modo a garantir a confidencialidade requerida.

A presente pesquisa mantém a confidencialidade das respostas dos entrevistados em razão da divulgação que se faz dos resultados e, portanto, de opiniões que podem não representar respostas adequadas frente a situações reais e sim opiniões. Outras razões dessa confidencialidade são inerentes à própria função do conselho fiscal.

Fontes Filho (2004) sustenta, que ao conselho fiscal compete exercer permanentemente a fiscalização sobre os órgãos da administração da companhia, no tocante às contas e à regularidade dos atos de gestão, prestando contas aos acionistas para que possam votar com conhecimento de causa nas assembléias.

O Instituto Brasileiro de Governança Corporativa - IBGC (2005, p.11) salienta que esse é um órgão que desfruta de autonomia em relação a seu congênere, ao afirmar que o conselho fiscal é "um órgão fiscalizador independente da diretoria e do conselho de administração, que busca, através dos princípios da transparência, equidade e prestação de contas, contribuir para o melhor desempenho da companhia". Em vista dessa atuação pública, os conselheiros fiscais têm responsabilidade perante os acionistas que representam e suas opiniões somente podem ser comunicadas aos stakeholders em publicações oficiais das entidades.

$\mathrm{Na}$ coleta de dados, elaborou-se questionário fechado com afirmativas de práticas evidenciadas no Guia de Orientação para o Conselho Fiscal produzido pelo IBGC em 2005, para que os respondentes indicassem sua percepção de adequação ou não das empresas aquelas práticas questionadas. Dividiu-se em três grupos de questões afirmativas: Competências e atribuições; pressupostos para boa atuação; relacionamentos do conselho fiscal. O conteúdo do questionário está apresentado juntamente com a análise dos dados.

A escala Likert foi adotada nesta pesquisa por permitir que uma série de afirmações relacionadas com o objeto pesquisado seja feita e que os respondentes manifestem o seu grau de concordância ou discordância em relação à afirmação aferida. Contudo, Seltiz et al. (1965) apresentaram desvantagens da utilização deste tipo de escala, tais como:

(1) é uma escala ordinal e por isso não permite dizer quanto um respondente é mais favorável que outro, nem medir o quanto de mudança ocorre na atitude, após a exposição dos respondentes a determinados eventos;

(2) diferentes padrões de respostas podem conduzir a resultados na escala idênticos, o que leva a duvidar se a mesma medição corresponde a 
atitudes idênticas. Divergindo dessa posição, Pinedo (1974) e Serrano (2002) afirmam que o uso da escala Likert permite ordenar e editar as informações de forma a eliminar as ambiguidades, duplicidades, irrelevâncias, inadequações e afirmações que dizem respeito a fatos ao invés de opiniões.

\section{Análise dos Dados}

O resultado da pesquisa traz o sentido expresso da percepção dos conselheiros fiscais das empresas listadas nos níveis 1, 2 e novo mercado, identificando-as se efetivamente aplicam ou não os princípios da governança corporativa.

O Conselho Fiscal como visto é um órgão de controle e em algumas vezes pode sobrepor às atividades desenvolvidas pela auditoria interna. Entretanto, a responsabilidade e o dever de informar aos acionistas cabe ao órgão colegiado. Analisando os dados por grupo de afirmativas, tem-se:

\section{Competências do conselho fiscal}

\section{Afirmativa 1 - Opinião sobre as demonstrações financeiras.}

As opiniões do CF devem contribuir para a vida da companhia e serem úteis, contribuindo para a boa fluidez dos seus processos. Tal fluidez recomenda que a opinião do CF seja conhecida pelo conselho de administração na reunião de aprovação das contas; por outro lado, tal fluidez recomenda a discussão prévia por parte do conselho fiscal não só das contas, mas também do relatório da administração e das notas explicativas.

Afirmativa 2 - Manifestação sobre o relatório da administração.

O Conselho fiscal deve manifestar-se preferencialmente antes da versão definitiva do relatório da administração com vistas à possibilidade de sugerir modificações ou inserções de conteúdo ou forma. O Conselho fiscal deve participar da reunião decisória do relatório. Se o conselheiro não tiver os elementos indispensáveis para sua opinião, deverá requerer tempo para tal.

Afirmativa 3 - Acompanhamento das decisões de investimento.

O Conselho fiscal, como parte de suas atribuições tem a obrigação de atender para as decisões de investimento e as relativas ao controle de risco. $\mathrm{O}$ objetivo da atenção é a fundamentação sobre as decisões tomadas, se são suficientes e adequadas e contemplam seus diferentes aspectos, como: comprometimento de capital de giro, garantia das fontes de financiamento. O objetivo não é o risco, mas sim o processo decisório.

Afirmativa 4 - Competências do conselho fiscal.

As atividades de competência do conselho fiscal estão normatizadas em 
um regimento interno, tornando claras suas responsabilidades e atribuições e prevenindo situações de maiores riscos, colaborando com os acionistas no controle dos administradores.

Figura 1 - Competências do conselho fiscal

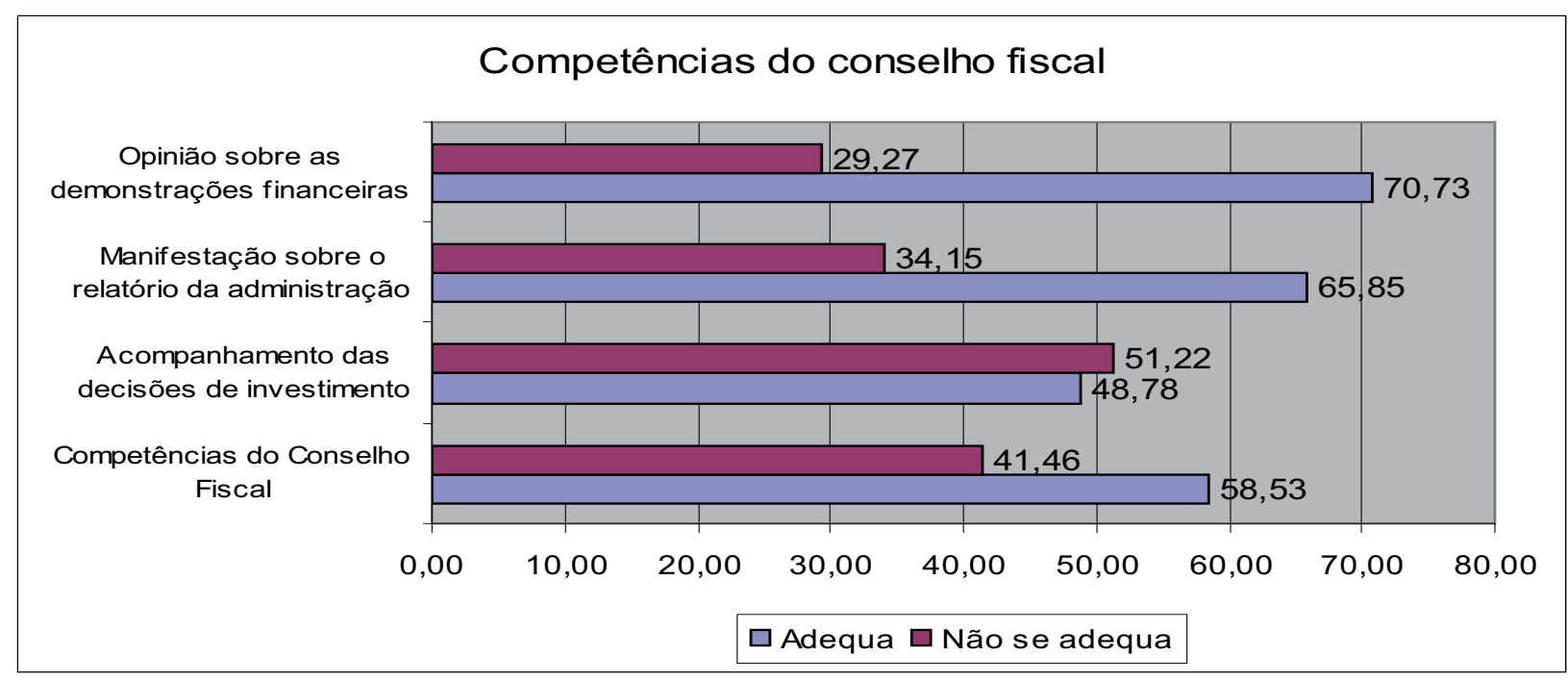

Fonte: Dados da pesquisa.

Os conselheiros pesquisados de certa forma entendem que as empresas em sua grande maioria se adequam às práticas de governança corporativa nas empresas, notadamente nas questões que se referem às opiniões das demonstrações financeiras (contábeis), no relatório da administração. Nestas duas primeiras afirmativas nenhuma novidade é demonstrada, pois são questões muito objetivas e presentes na legislação das sociedades por ações. As competências do conselho fiscal apresentam uma proporção de $58,53 \%$ das opiniões que as empresas se adequam. Essas competências estão relacionadas exclusivamente àquelas previstas na legislação das sociedades anônimas e, disso as empresas não podem escapar.

Como a legislação, apesar de obrigar a existência do conselho fiscal é flexível em sua instalação, ela ocorre sempre que existe um conflito na estrutura de poder. Ficou marcado para as organizações que os conselheiros não são profissionais que estão ali para colaborar no controle, mas sim para servir de olheiro dos acionistas em conflito. Tal assertiva apesar de não ser unânime e não representar o universo em estudo, faz parte da cultura empresarial visto que $40 \%$ das empresas pesquisadas não dispõe desse órgão instalado.

A questão colocada relativa ao acompanhamento das decisões de investimento, $51,22 \%$ dos conselheiros entende que as empresas não se adequam a essa prática. Esse tópico relaciona-se às questões estratégicas e as empresas por entender que os conselheiros fiscais não devem opinar nessa área, dificultam ou impedem seu acesso sob alegação de informações sigilosas, como se os conselheiros fiscais fossem espiões invasores. Demonstra que a figura dessa classe ainda 
não é muito bem aceita nas organizações.

No tópico das competências do conselho fiscal, resume-se notadamente na questão da organização da estrutura e na efetiva atuação. Desta feita, 41,46\% dos respondentes entendem que as empresas não se adequam o que se denota que no tópico está relacionada a questão da avaliação dos riscos e do controle da organização, pontos ainda escuros e muito discutidos na avaliação da competência. Fatores de graves discórdias nas relações dos órgãos.

Nesse aspecto a questão dos riscos e controles estão muito longe da interpretação das empresas como instrumento de atuação dos membros do conselho fiscal.

\section{Pressupostos para boa atuação do conselho fiscal}

\section{Afirmativa 5 - Independência}

O conselheiro deve ter independência técnica, econômica e de vínculos para com os acionistas e para com a companhia. Tem atuação fiscalizadora independente e não pode tornar a função instrumento de abuso por parte de minoritários com interesses particulares.

Afirmativa 6 - Regimento interno e agenda.

Dada a natureza do órgão, recomenda-se que o conselho tenha uma norma para funcionamento interno sem restrição à atuação individual. Regras como: pauta mínima, momento do registro da ata; agenda de trabalho e presidência do colegiado.

Afirmativa 7 -Integração dos conselheiros.

Cada novo conselheiro deve passar por um programa de introdução à companhia e receber documentos com os seguintes pontos além de outros julgados necessários: a) dados da empresa; b) apresentação dos conselheiros - currículo; c) datas e horários de reuniões; d) regras para as reuniões; e) periodicidade e previsão para reuniões especiais; f) demonstrações financeiras anteriores com a cópia de recomendações da auditoria; g) plano de trabalho da auditoria independente; h) plano de negócio; i) reunião com diretoria e conselho de administração para integração.

\section{Afirmativa 8 - Consultas externas}

Os conselheiros têm direito de fazer consultas e solicitar relatórios produzidos por profissionais externos, pagos pela empresa para obter uma segunda opinião sobre tópicos em análise.

\section{Afirmativa 9 - Convidados para reuniões}

Pessoas chaves dentro da empresa são convidadas ocasionalmente para as reuniões do conselho fiscal para serem questionadas sobre determinados assuntos importantes. 
Afirmativa 10 - Fatores determinantes para boa atuação

A eficácia do conselho é determinada por um conjunto de fatores: a) competência dos conselheiros para atuação crítica e construtiva no campo financeiro, de negócio; b) conhecimento das melhores práticas de governança corporativa; c) critérios de indicação; d) existência no conselho de pelo menos um membro qualificado nas áreas de contabilidade e finanças; e) transparência por parte da empresa para com as informações necessárias ao pleno desempenho; f) pró atividade na busca de informações relevantes para formação de juízo.

Figura 2 - Pressupostos para boa atuação do conselho fiscal

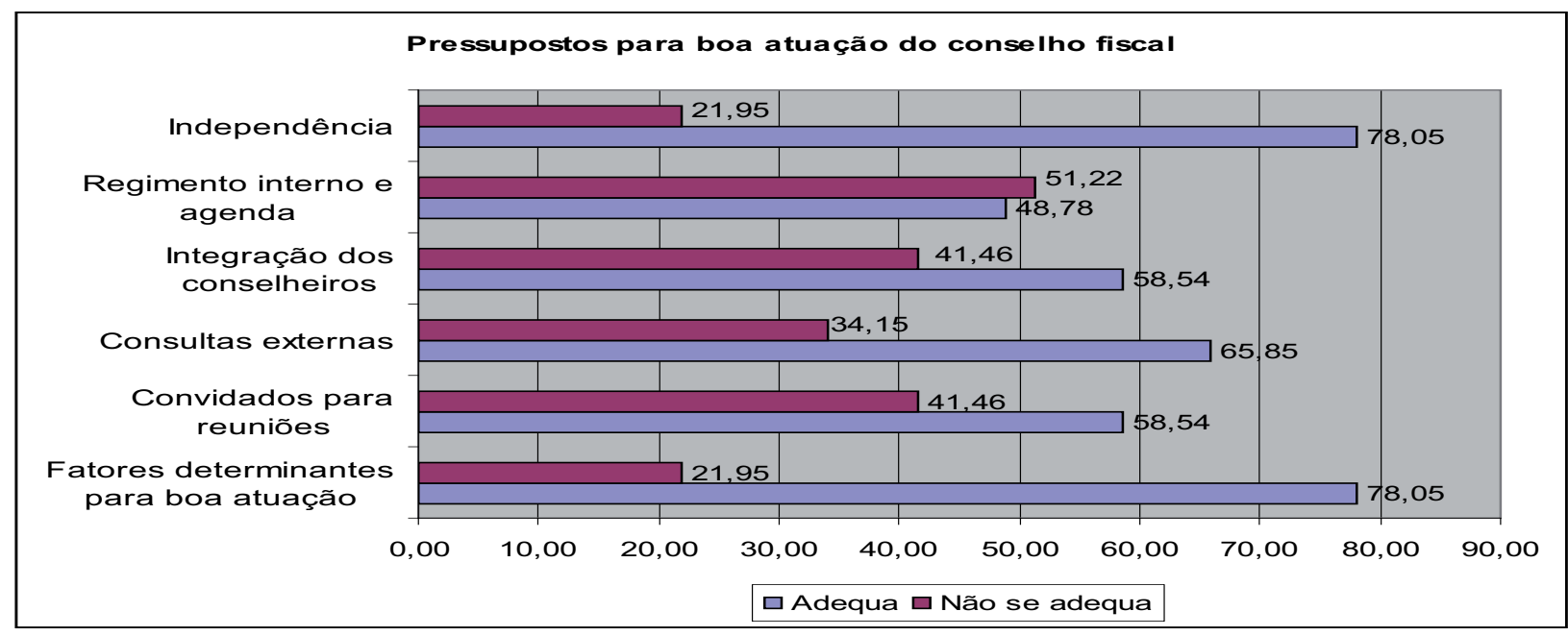

Fonte: Dados da pesquisa.

Os pressupostos para atuação dos membros do conselho fiscal estão relacionados aos trabalhos que são desenvolvidos nas empresas com objetivo de extrair o maior numero de informações para que esse colegiado tenha um juízo de valor e, assim fixar seu voto. A independência cujo resultado supera $78 \%$ dos respondentes não poderia ser outro, pois retrata uma posição individual.

Esse tópico a total independência técnica e profissional que o conselheiro deve ter com a empresa, ligados ou coligados, sob pena de sua atuação ser colocada em desconfiança, demonstra que $21,95 \%$ dos respondentes entendem que as empresas não se adequam. Comparativamente alta a diferença entre adequação e não adequação é uma percepção negativa muito alta em se tratando de empresas de nível elevado no entendimento da governança corporativa. A questão do regimento interno e a agenda é um tópico mais de organização na estrutura que outro aspecto e demonstra um equilíbrio entre as opiniões - $51,22 \%$ não se adequam e $48,78 \%$ se adequam. Essa questão leva a possibilidade de conflito entre os pares e a estrutura já que não existindo uma agenda de atividades e nenhum regramento de atuação, os conselheiros acabam atuando em uma forma desorganizada enquanto colegiado e de conduta própria considerando a autonomia para 
formação de juízo.

Para as empresas, tal prática facilita uma negativa de acesso a informações sob alegação de não estar nas atribuições legais do atuante, dificultando assim uma atuação séria e tranqüila por parte do conselheiro, demonstrando com isso a força que os controladores podem ter, inclusive em um órgão de controle.

Nesse sentido, os conselheiros ainda não correspondem a uma organização já que $51,22 \%$ dos respondentes entendem que não dispõem de um regimento e, ainda de uma agenda de trabalho eficiente. Na questão da integração, 58,54\% entendem que as empresas se adequam no tópico o que significa que os conselheiros sofrem processos de integração interna com a organização antes do inicio de seus mandatos.

As consultas externas que correspondem a esclarecimentos com agentes da organização ou fora dela, como consultoria jurídica, auditoria independente, auditoria interna, financeiro são admitidas por $65,85 \%$ dos consultados que as empresas se adequam à essa prática de admitir que os conselheiros façam incursões independentes.

Da mesma forma expõem que 58,54\% dos respondentes entendem que as empresas admitem que se convidem pessoas de outros órgãos da organização para esclarecimentos sobre tópicos que agucem ao colegiado.

\section{Relacionamento do conselho fiscal}

Afirmativa 11 - Relacionamento com comitê de auditoria, auditoria independente e interna

A integração das ações do conselho fiscal e do comitê de auditoria é fundamental quando os dois órgãos coexistem na empresa, conciliando interesses, objetivos, regimento interno e calendário. Com a auditoria interna será fundamental para a boa atuação quando inexistente o comitê de auditoria. É boa prática a realização de reuniões conjuntas entre o comitê de auditoria e o conselho fiscal, com a auditoria independente para discussões de assuntos de interesse mútuo.

Afirmativa 12 - Relacionamento com a diretoria

Os administradores podem utilizar-se do conselho fiscal como uma instância protetora e vigilante para inibir atos e procedimentos; é mais uma instância de diálogo para os administradores. Na sua atuação deve ter o cuidado de não interferir nas decisões de gestão e tampouco no direcionamento estratégico, papéis que cabem aos gestores e ao conselho de administração. Devem ser estabelecidos mecanismos que assegurem a informação ao conselho fiscal sobre quando deve se fazer presente a uma reunião do conselho de administração ou da diretoria.

Afirmativa 13 - Relacionamento com o conselho de administração.

É boa prática o conselho fiscal reunir-se periodicamente com o conselho 
de administração para tratar de assuntos de interesse comum, com fim de mútuo apoio e auxilio na compreensão dos temas críticos que afetam o processo decisório da companhia, além daquele determinado pela lei sobre os quais o conselho fiscal obrigatoriamente deve decidir.

Afirmativa 14 - Relacionamento do conselho de administração na contratação de auditoria independente

O conselho de administração negocia com os auditores independentes, estabelece o programa de auditoria e acerta preço e prazo, comunicando e colocando à disposição dos membros do conselho fiscal as diretrizes ajustadas.

Afirmativa 15 - Relacionamento com comitês.

Existem diferentes comitês, cada um com alguns membros do conselho de administração, formados para estudar determinados assuntos que demandam analises mais complexas. O conselho fiscal, ao final, recebe relatórios conclusivos sobre as deliberações ou orientações dos comitês.

Figura 3 - Relacionamento do conselho fiscal

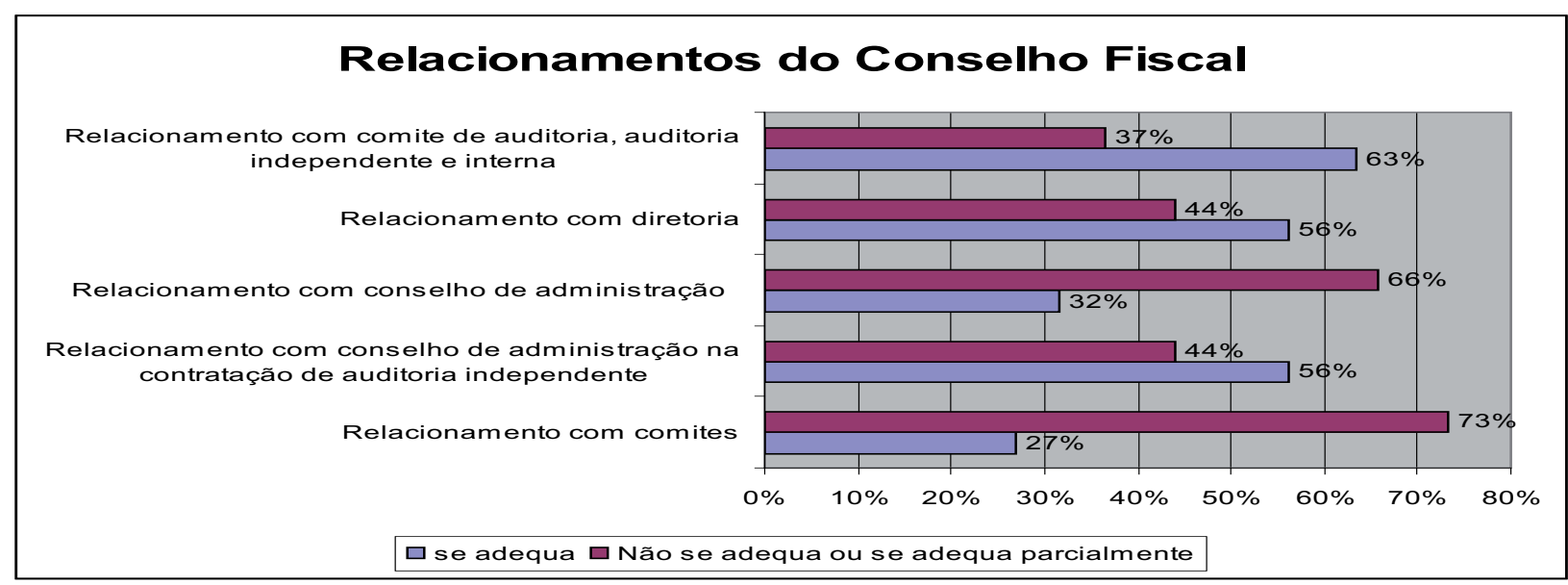

Fonte: Dados da pesquisa.

Uma questão de governança está explicita nesta pesquisa quando se trata do relacionamento do conselho fiscal com o conselho de administração, em que $68 \%$ dos respondentes entendem que as empresas não se adequam a essa prática, entendendo-se o conflito entre fiscalizado e fiscalizador.

A atribuição do conselho fiscal, eleito em assembléia de acionistas está para fiscalizar os atos do conselho de administração, de forma direta e, desta, causam atritos e impossibilidades que culminam na quebra de ambiente na relação dos órgãos.

Pela falta de instrumentos legais, os fiscalizados entendendo possuírem maior poder na estrutura, não atendem aos chamados dos fiscalizadores. Complicada ainda mais quando é nítida a existência de conflito entre majoritários e minoritários e a composição do colegiado mantém essa diferença, dificultando 
ainda mais a atuação individual do conselheiro e, impedindo suas demandas ao colegiado. A mesma análise se faz com o relacionamento com os comitês, cujo objetivo é avaliar as decisões dos conselheiros nesses comitês se estão de acordo com os interesses dos acionistas.

Na mesma linha, avaliou que 73\% dos respondentes entendem que as empresas não se adequam à pratica de relacionamento com os comitês do conselho de administração. Notadamente em razão da interpretação da legislação em que os assuntos discutidos naquele conselho não são de interesse do órgão fiscalizador cujo papel deve ater-se exclusivamente a questões contábeis.

Não causa estranheza na questão da contratação da auditoria, em que 56\% dos respondentes indicam que as empresas se adequam a essa prática. Nota-se que a questão envolve apenas a questão da contratação, ou, a apresentação do contrato e limitações contratuais da empresa de auditoria, não estando indicado o escopo do trabalho e a possível orientação do conselho fiscal na elaboração do projeto.

Nos demais quesitos do relacionamento do conselho fiscal: com a auditoria interna e independente $(67 \%)$, com a diretoria (56\%) e na contratação da auditoria independente (56\%) são considerados normais e que as empresas se adequam às normas.

\section{Considerações Finais}

A pesquisa evidenciou uma série de elementos que demonstram as relações conflitantes entre os órgãos: conselho de administração e conselho fiscal.

Apresentou que as empresas de forma geral se adequam às práticas de governança corporativa recomendadas, na visão dos conselheiros fiscais, à exceção daqueles tópicos que não são claros na legislação.

Sendo um órgão de instalação não obrigatória e apenas com a vontade de acionistas com pelo menos $10 \%$ do capital votante, um expressivo número de empresas não mantém instalado esse conselho, concluindo que sua aplicação dá-se apenas quando existe algum tipo de conflito de agência.

Nesse sentido, porém, o estudo da KPMG (2008), quanto ao Conselho Fiscal, evidenciou que:

1. A grande maioria (cerca de $76 \%$ ) das empresas com ADRs possuem Conselho Fiscal instalado. No outro extremo, observou-se que menos da metade das empresas pertencentes ao Novo Mercado (cerca de 40\%) possuem tal órgão de fiscalização em funcionamento;

2. Em relação à composição, observou-se que cerca de $47 \%$ dos conselheiros fiscais das empresas com ADRs foram indicados por acionistas minoritários, contra 36\% no grupo de empresas do Novo Mercado e apenas 19\% no grupo de empresas representativas da população de 
listadas na Bovespa.

Demonstrou pela pesquisa bibliográfica que as atribuições previstas em Lei ao conselho fiscal não são claras, aprofundando as crises de relacionamento na estrutura de poder, notadamente quando existe acionista minoritário x acionista majoritário.

Demonstrou que as empresas se dispõem a cumprir os conceitos difundidos da governança corporativa sem, no entanto incluir o órgão do conselho fiscal à exceção daquelas ações que são claras e objetivas na legislação.

Entendem que o conselho fiscal é um mero ratificador do relatório da auditoria independente e está apenas para avaliar e verificar os livros contábeis sem que tenham condições de entender as questões estratégicas da organização.

Os conselheiros fiscais reconhecem de fato que suas atividades quando possíveis, efetivamente geram valor aos acionistas no princípio que os interesses destes são acompanhados e controlados via conselho de administração.

Por ser independente o conselho fiscal pode atuar mais livremente na avaliação dos riscos e controles internos.

Com base na análise da pesquisa, verifica-se que a atuação do Conselho Fiscal, a partir das novas exigências do mercado de capitais e, portanto, do interesse dos acionistas, precisa passar por um processo democrático nas empresas em razão de reforçar os mecanismos para o exercício da pluralidade de interesses. Reconhecer a importância de propostas divergentes, estimular o estabelecimento de processos de convergência e apoio aos objetivos estabelecidos com vistas à maior eficiência e efetividade da atuação dos conselheiros fiscais.

Fundamentos como o movimento democrático, participação, informação e consciência fortalecem-se as bases para o funcionamento adequado do Conselho Fiscal. Procura-se, dessa forma, o exercício de monitoramento dos executivos e técnicos, alinhamento de interesses, redução de problemas de assimetria de informações e risco moral.

Pode ser lícito afirmar que a permanência em determinado nível de governança de uma entidade poderia estar associada à qualidade e efetividade do conselho fiscal.

A opinião do Conselho Fiscal não pode ser negligenciada, mas, sim, avaliada periodicamente pelo Conselho de Administração e tomadas as providências necessárias.

Ao término do artigo faz-se necessário listar algumas limitações presentes em pesquisas desta natureza:

1. Das 46 empresas às quais foram encaminhadas correspondências para diretores de relações com investidores, 19 não responderam ou responderam que não poderiam atender, encaminhando os endereços de e-mail por falta de autorização dos conselheiros; 
2. Às demais, com os endereços recebidos, foram encaminhados questionários, no total de 81 e-mails;

3. Desse total de 81 e-mails enviados, apenas 41 responderam ao questionário, 05 responderam que não participariam da pesquisa. No que tange aos demais, sequer se manifestaram, apesar de que, para cada conselheiro em média, foram enviados pelo menos 03 e-mails, pedindo a participação na pesquisa.

No que concerne a sugestões para novas pesquisas, considerando que nessa não houve a preocupação de identificar o porte da empresa, o mercado de atuação e, principalmente a classificação enquadrada, sugere-se:

1. Envidar os melhores esforços para a identificação dessas variáveis por níveis de adesão ao novo mercado, por ramo de atuação e porte;

2. Identificar a opinião dos demais atores/participantes: conselho de administração, acionistas minoritários, controladores e, ainda, a diretoria executiva.

\section{Referencias}

ALCHIAN, A; DEMSETZ,H. Production, information costs and economic organization. American Economic Review, 1972 v. 62, p. 777-795

ALLEN,F.; GALE, D. Comparing financial system. Cambridge, Massachusetts: Mitt Press, 2000.

ALMEIDA, F. G. de. Governança Corporativa no Brasil - Criação de valor com base na gestão corporativa - um estudo de caso do setor de telecomunicações. 2001. Dissertação (Mestrado em Administração) Pontifícia Universidade Católica do Rio de Janeiro. Rio de Janeiro, 2001.

ANDRADE, Adriana; ROSSETTI, José Paschoal. Governança corporativa: fundamentos, desenvolvimento e tendências. S. Paulo: Atlas, 2004.

BERLE, A.; MEANS, G. The modern corporation and private property. New York: Mc. Millan, 1932.

BERNHOEFT, R.;GALO, M. Governança na empresa familiar. $4^{\text {a }}$ Edição. Rio de Janeiro: Ed. Elsevier, 2003.

BEUREN, Ilse Maria (org.) Como elaborar trabalhos monográficos em contabilidade. São Paulo. Ed. Atlas, 2004.

BORNHOLDT, W. Governança na empresa familiar: implementação e prática. 
Porto Alegre: Bookman, 2005.

BOOZ ALLEN, HAMILTON. Panorama Atual da governança corporativa no Brasil. Quarto Congresso Brasileiro de Governança Corporativa. São Paulo: 10/11/2003. Disponível em: www.google.com. Acesso em: 11/11/2011.

BRANDÃO, M. Mansur. Governança Corporativa e a influência dos acionistas minoritários no sistema de decisões estratégicas, 2004. Dissertação. (Mestrado em Administração). Pontifícia Universidade Católica de Minas Gerais. Belo Horizonte/MG.Belo Horizonte/MG, 2004.

BRASIL, Lei 10.303 de 31/10/2001. Altera dispositivos da Lei 6.404/76 - Lei das Sociedades Anônimas. Disponível em www.planalto.gov.br. Acesso em: 22 de abr. 2006.

BRASIL, Lei 9.457 de 05/05/1997. Altera dispositivos da Lei 6.404/76 - Lei das Sociedades Anônimas. Disponível em www.planalto.gov.br. Acesso em: 22 de abr. 2006.

BRASIL, Lei 6.404/76 de 15/12/1976. Dispõe sobre as Sociedades Anônimas. Disponível em www.planalto.gov.br . Acesso em 22 de abr. 2006.

BULGARELLI, W. Regime jurídico do conselho fiscal das S.A. Rio de Janeiro: Renovar, 1998.

CAMPOS, E. Á. S. Introdução. In: Campos, Elismar Álvares da Silva. (Org.). Governando a Empresa Familiar. 1 ed. Rio de Janeiro (RJ): Qualitymark; FDC, 2003, v. 1, p. 11-16.

DUARTE, JR, A.M. Risco: definições, tipos, medição e recomendações para seu gerenciamento. Trabalho interno de instituição financeira, Unibanco. São Paulo, 2003.

FONTE FILHO (2004), Como Andam as Práticas de Gestão e Governança dos Fundos de Pensão no Brasil. IN: $25^{\circ}$ Congresso da ABRAPP, Outubro, Fortaleza, Instituto Brasileiro De Governança Corporativa (CE). Guia de orientação para o conselho fiscal. São Paulo: IBGC, 2005.

HARRIS, M.;TOWSEND, R.M. Resource allocation under asymmetric information. Econometrica, p. 33-64, 1981.

HART, O.; MOORE, J. Debt and Seniority: an analisys of the role of hard clair$\mathrm{ms}$ in constraining management. American Economic Review. V. 85 p. 567-585, 
$1995 \mathrm{a}$.

IBGC - INSTITUTO BRASILEIRO DE GOVERNANÇA CORPORATIVA Guia de Orientação para o Conselho Fiscal. Disponível em: www.ibgc.org.br. Acesso em: 08 abr. 2005.

KANITZ, S.C. KANITZ, L.M. A relação pai e filho nas empresas familiares. Revista de Administração. São Paulo. FEA/USP, V.13, No 1, p.33-41, jan./mar. 1978.

KPMG. A governança corporativa e o mercado de capitais: um panorama atual das corporações brasileiras na Bovespa e nas Bolas norte-americanas. Pesquisa da KPMG Auditores Independentes em 2008. Disponível em: http:/www.fipecafi.org/ palestras/ceg-ciclo-de-debates-em-governanca-corporativa-a-governanca-corporativa-e-o-mercado-de-capitais/estudo-kpmg-ceg.pdf . Acesso em: 12/11/2011.

LA PORTA, R. et al. Law and finance. Journal of Political Economy, v. 106, p.1113-1155, 1998.

54, p. 471-518, 1999.

Corporate ownership around the world. Journal of Finance, v.

LAMB, Roberto. Modelagem para uma investigação da efetiva função do conselho fiscal nas sociedades por ações brasileiras - relatório de pesquisa. EA/UFRGS, Porto Alegre, 2002.

LEAL, Ricardo Pereira Câmera; SILVA, André Luiz Carvalhal; VALADARES, Silvia Mourthé. Estrutura de Controle das Companhias Brasileiras de Capital Aberto. RAC, v. 6, n. 1, Jan./Abr. 2002: 07-18.

LEAL, R.; VALADARES, A. Ownership, control and corporate valuation of brazilian companies. OECD. Working Paper, Abr./2002

LODI, João B. Governança Corporativa: o governo da empresa e o conselho de administração. São Paulo: Ed. Campus, 2005.

. A empresa familiar. São Paulo. Pioneiras, 1998.

MARCH, J.G. SHAPIRA, Z. Managerial perspectives on risk and risk taking. Management Science, v.33, No 11. nov/1987.

MARTIN, N.C. SANTOS, L.R. DIAS FILHO, J.M. Governança empresarial, riscos e controles internos: a emergência de um novo modelo de controladoria. Revista de Contabilidade e Finanças. São Paulo. No 34, p. 7-22, jan-abr/2004. 
MARTINS, G.A. Manual para elaboração de monografias e dissertação. São Paulo. Ed. Atlas, 2002.

MÔNACO, D.C. Estudo da composição dos conselhos de administração e instrumentos de controle das sociedades por ações no Brasil. 2000. Dissertação de Mestrado da Faculdade de Economia, Administração e Contabilidade da Universidade de São Paulo, São Paulo. 2000.

OLIVEIRA, Djalma de Pinho Rebouças de. Governança corporativa na prática. São Paulo: Atlas, 2006.

PINEDO, Ignacio F. de. Construcción de una escala de actitudes tipo Likert. NTP 15. Instituto Nacional de Seguridad e Higiene en el Trabajo. Disponível em www. mtas.es/insht/ntp/ntp_015.htm. Acesso em 30/09/2005.

RAJAN, R.; ZINGALES, L. The Governance of the New Enterprise. In Corporate Governance, Ed, Vives, X., Cambridge University Press, 2000.

ROSS, S.A. The economic theory of agency: the principal's problems. American Economic Review, v. 63, No 2, 1973.

SANTOS, Eduardo José dos; ROGERS, Pablo; MACHADO, Lúcio de; LEMES, Sirlei. Análise das questões à proteção dos acionistas minoritários na reforma à lei 6404/76. Trigésimo Encontro da ANPAD, 23 a 27 de setembro de 2006, Salvador/ Bahia. - Enanpad 2006.

SANTOS, H.M. Relatório de resultado de pesquisa sobre governance corporative no Brasil. São Paulo: IBCA, 1998.

SERRANO, G.P. Investigación cualitativa: retos e interrogantes. Madrid: Editorial La Muralla, 2002.

SIFFERT FILHO, N. Governança corporativa: padrões internacionais e evidências empíricas no Brasil nos anos 90. Revista do BNDES, n. 9, 1998.

SILVEIRA, Alexandre Di M. Governança corporativa e estrutura de propriedade. São Paulo: Saint Paul Institute of Finance, 2006.

SOUZA, M.S. Governança Corporativa: perspectivas no Brasil. Adcontar. Belém, v.5 No 1 p. 15-34, jun/2004.

STRAHOTA, R.D.; TAFARA, E. Promoção de consenso internacional sobre práticas regulatórias. Journal USA. 2005. 
TEDLOW, R.S.; John JR, R. Managing Big Business. Harvard Business School Press, 1986.

VALVERDE, T.de M. Parecer: sociedade anônima. Exame de livros: conselho fiscal; responsabilidade civil dos diretores. Revista Forense, N 137, p. 50-57, Rio de Janeiro, 1959. 
